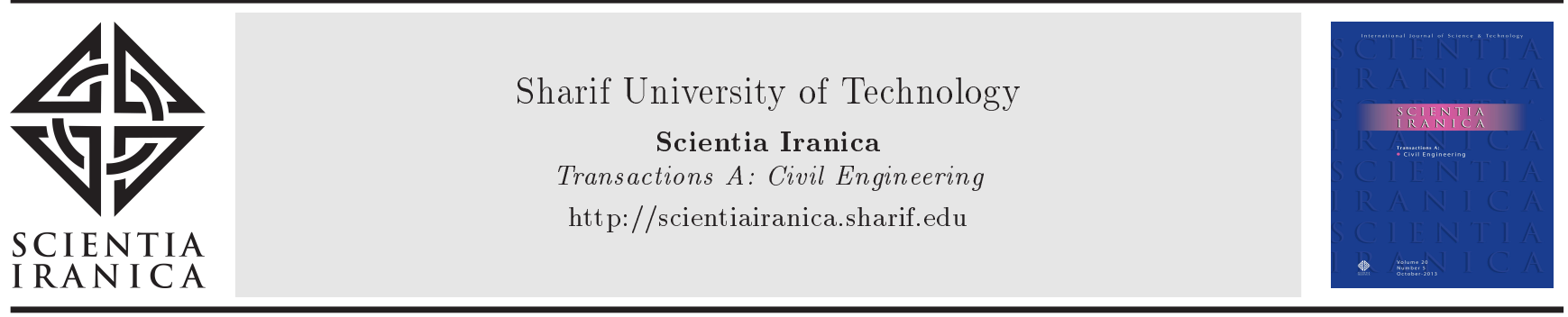

\title{
Development of a new integrated method for generation of IDF curves based on three scenarios of climatic changes
}

\author{
A. Adib* and S. Ghafari Rad \\ Department of Civil Engineering, Faculty of Engineering, Shahid Chamran University of Ahvaz, Iran.
}

Received 11 June 2017; received in revised form 24 July 2017; accepted 3 November 2017

\section{KEYWORDS \\ Climatic change; \\ The HadCM3; \\ IDF curves; \\ RBF ANN; \\ The Baghmalek \\ climatic station; \\ The Gumbel \\ distribution.}

\begin{abstract}
Climate change can change the Intensity-Duration-Frequency (IDF) curves. This research study evaluates IDF curves changes of the Baghmalek climatic station in the southwest of Iran. A developed integrated method extracted the IDF curves using the Gumbel and log-Pearson III probability distributions and observed maximum annual precipitations. Durations of these precipitations are 15, 30, 45 minutes and 1,2,3,6 and 12 hours. For this purpose, this method utilizes the recorded precipitation data of the Baghmalek climatic station in a 40-year period (1974-2013). Then, mean square error method determines the probability distribution that has the best fitting with this data. The HadCM3 prepares precipitation data for a 30-year period (2021-2050) based on A1B, $\mathrm{B} 1$, and $\mathrm{A} 2$ scenarios. In addition, this method selects an optimum artificial neural network to extract maximum annual rainfall intensity for different durations and scenarios. Then, selected network and the chosen probability distribution produce IDF curves for different return periods and scenarios. Produced IDF curves for different scenarios are compared to IDF curves of a base time period. Because of increasing carbon dioxide and its greenhouse effects in these scenarios, rainfall intensity will increase for return periods less than 2.33 years, while it will decrease for return periods more than 2.33 years.
\end{abstract}

(C) 2019 Sharif University of Technology. All rights reserved.

\section{Introduction}

In recent decades, high growth rate of population and industrialization of human societies have increased the concentration of greenhouse gases as dioxide carbon in the atmosphere, which changed mean, maximum, and minimum temperature as well as average annual precipitation in different countries. Because of special weather conditions and large oil resources in the Middle East, effects of climatic changes on these countries are

*. Corresponding author.

E-mail address: arashadib@scu.ac.ir (A. Adib);

saeid_ghafari90@yahoo.com (S. Ghafari Rad)

doi: $10.24200 /$ sci. 2017.4593 greater than those on other countries are. For example, Khuzestan province in the southwest of Iran has the largest oil resources and steel industries available in Iran. This province is Iran's industrial center. Because of climatic changes in recent years, severe dust storms often occur in this province. Intensity of these storms is unprecedented, starting from 2006. Climatic changes can affect hydrologic characteristics of different watersheds; for example, IDF curves can change.

This research has three different aspects (generation of IDF curves, use of General Circulation Model (GCM), and investigation of effects of climatic changes on IDF curves), while other researchers usually consider one or two aspects in their studies. To study IDF curves and use probability distributions or empirical relationships for generation of these curves, 
the research studies such as: Garcia-Bartual and Schneider [1] in Spain, Yu et al. [2] in Taiwan, Madsen et al. [3] in Denmark, Agilan and Umamahesh [4] in India, Huang et al. [5] in Malaysia, Fadhel et al. [6] in England, and Bezak et al. [7] in Slovenia should be consulted. Yu et al. [2] used scaling theory and Gumbel probability distribution to generate regional IDF formulas at 46 rain gauge stations of northern Taiwan. They considered annual 1-day maximum series for scaling theory. In their research, the study area was divided into three homogenous regions. Their results showed that the regional IDF scaling formulas proposed suitable results in simulation and verification.

Khan et al. [8] in Canada, Wang and Lau [9] in United State of America (USA), Hashmi et al. [10] in New Zealand, and Gulacha and Mulungu [11] in Tanzania utilized GCM and different downscaling methods to predict future climatic data (such as rainfall, temperature, etc.). Gulacha and Mulungu [11] utilized the Statistical Down Scaling Model (SDSM) for downscaling of prepared data by GCM model in the WamiRuvu River Basin. They considered the base time period of 1961-1990 and used the HadCM3 to prepare precipitation and temperature data in the $2020 \mathrm{~s}, 2050$ s, and $2080 \mathrm{~s}$ based on B2 and A2 scenarios. They showed that annual and monthly precipitation and maximum temperature would increase and minimum temperature would decrease or increase in the future.

In addition, Kuok et al. [12] in Malaysia, Mailhot et al. [13] in Canada, Alam and Elshorbagy [14] in Canada, Kuo et al. [15] in Canada, Lima et al. [16] in Korea, Agilan and Umamahesh [17] in India, Simonovic et al. [18] in Canada, and DeGaetano and Castellano [19] in U.S.A. applied GCM and different downscaling methods to generation of IDF curves. Mailhot et al. [13] applied the Canadian Regional Climate Model (CRCM) to evaluate effects of climatic changes on IDF curves (from 2041 to 2070) in Southern Quebec. The base time period of this research was 1961-1990. They considered annual maximum rainfall data time series from May to October, and durations of precipitation included 2, 6, 12, and 24 hours. They showed that return periods of 2-, 6-, 12-, and 24-h rainfall events (for constant rainfall intensity) would decrease in the future.

This study develops a new integrated method (using GCM model, RBF neural network, and different probability distributions) to generate IDF curves of different scenarios of climatic changes that may occur in the future. For this purpose, this method utilized generated data by a GCM and a RBF artificial neural network. The HadCM3 (Hadley Centre Coupled Model, version 3) and RBF-ANN generate maximum annual rainfall intensity for different durations and scenarios in the next years. At the end, a suitable probability distribution (Gumbel probability distribu- tion) produces IDF curves. Most research studies use rainfall-runoff models to extract necessary information from generated data by GCM; however, this study utilizes a RBF-ANN for this purpose. This study takes the following steps:

1. Preparation of precipitation data in a 40-year period (1974-2013) and determination of IDF curves using a suitable probability distribution;

2. Extraction of climatic data using HadCM3 model for three scenarios (A1B, B1, and A2) in a 30-year period (2021-2050);

3. Determination of maximum annual rainfall intensity for different durations and scenarios in the next years (2021-2050) using extracted data by HadCM3 model and a suitable RBF ANN;

4. Determination of IDF curves of three scenarios using selected probability distribution in step 1 ;

5. Comparison of IDF curves of three scenarios and IDF of the base time period (1974-2013).

\section{Materials and methods}

\subsection{Case study}

The Baghmalek is a city in Khuzestan province, located in southwestern part of Iran. The Baghmalek watershed is a part of the Zard River watershed. The Zard River is a tributary of the Jarahi River. The Baghmalek watershed is located between $49^{\circ} 39^{\prime}$ to $50^{\circ} 11^{\prime}$ E longitude and $31^{\circ} 22^{\prime}$ to $31^{\circ} 42^{\prime} \mathrm{N}$ latitude. The area of this watershed is $884 \mathrm{~km}^{2}$. Maximum, mean, and minimum heights of this watershed are 3303.3, 1197, and $391.7 \mathrm{~m}$, respectively. Mean annual temperature and precipitation rates are $27^{\circ}$ and $450 \mathrm{~mm}$, respectively. Figure 1 illustrates Baghmalek watershed and its location in Khuzestan province, Iran.

\subsection{Research methodology}

\subsubsection{The HadCM3 (Hadley centre Coupled Model,} version 3)

The HadCM3 is a coupled atmosphere-ocean general circulation model (AOGCM). This model was developed at the Hadley Centre in the United Kingdom and has two components (the atmospheric model HadAM3 and the ocean model HadOM3). The HadOM3 has a sea ice model. In addition, this model does not need to do flux adjustment to improve simulation. For simulation, this model assumes that the number of days in a year is 360 days (each month is 30 days). Advantages of this model include high resolution of HadOM3 and good coordination between HadOM3 and HadAM3 [21-23]. 


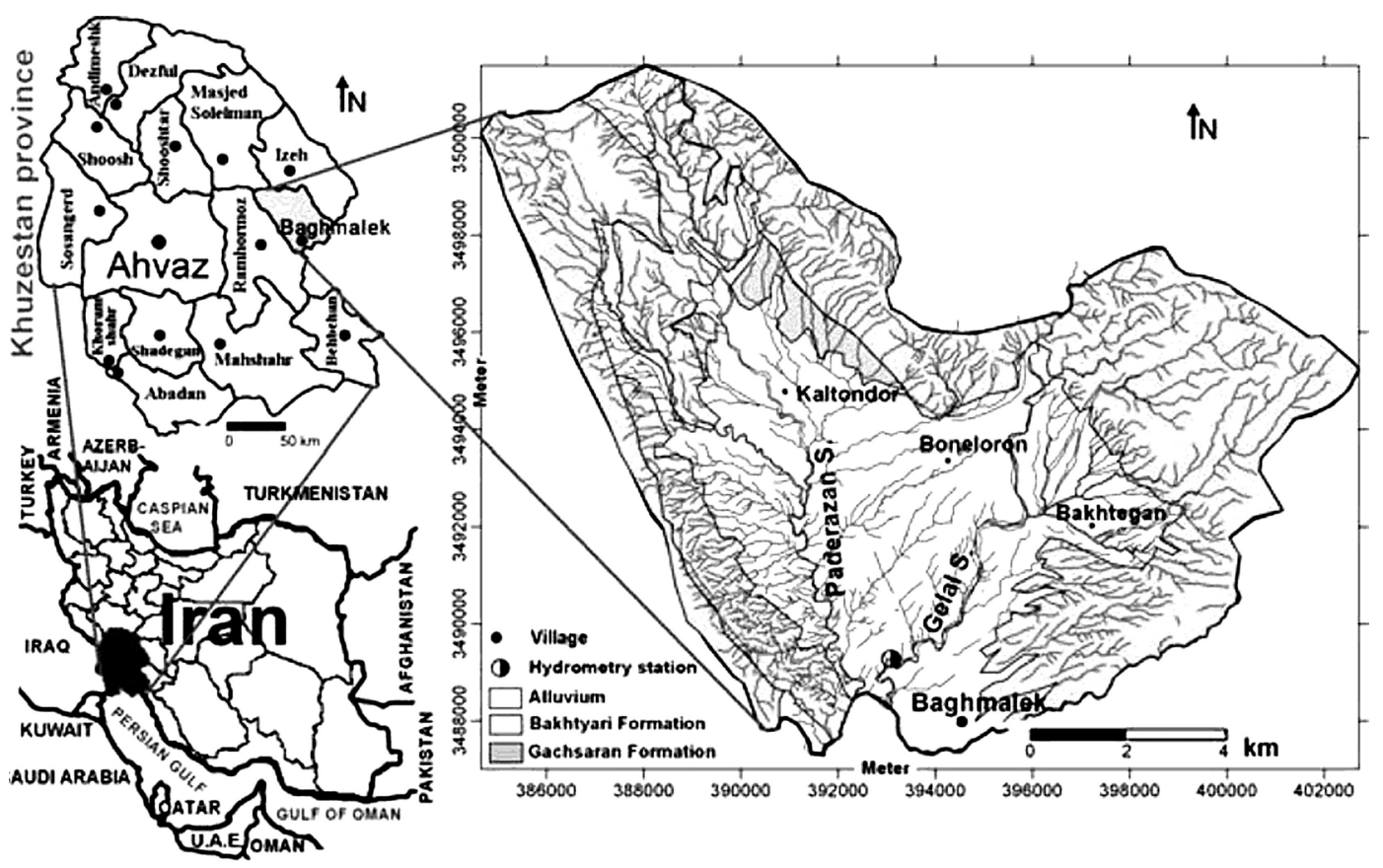

Figure 1. The Baghmalek watershed and its location in Khuzestan province, Iran [20].

\subsubsection{The Special Report on Emissions Scenarios (SRES)}

The Intergovernmental Panel on Climate Change (IPCC) published a report (SRES) in 2000. This report described scenarios concerning greenhouse gas emission. These scenarios can be used to predict climatic changes in the future. In addition, IPCC published the IPCC Third Assessment Report (TAR) in 2001 and the IPCC Fourth Assessment Report (AR4) in 2007. TAR and AR4 described four scenarios (A1, A2, B1, and B2). In this research, three scenarios have considered A1B, B1, and A2. The A1 scenario family predicts the following:

1. A very rapid growth of economy in the future;

2. The peak of global population to occur in the midcentury;

3. A decrease in population after the mid-century.

In this scenario, new and more efficient technologies will develop very rapidly. Differences in the income per capita between developed and developing countries will reduce, and cultural and social interactions will increase among different regions of the world. The A1 scenario family is divided into three groups, which are dependent on technological change in the energy system. The three A1 groups include fossil intensive (A1FI), non-fossil energy sources (A1T), or a balance across all sources (A1B).

The A2 scenario family predicts a very heterogeneous world. Characteristics of this scenario include self-reliance and preservation of local identities. The population is increasing continuously. Economic development is not global and is different in developed and developing countries. Per capita economic growth and technological change are more fragmented and slower than other scenarios.

The B1 scenario family predicts a convergent world. The peak of global population is in midcentury and will decrease after the mid-century (as the A1 scenario); however, with rapid changes will be observed in economic structures toward a service and information economy, a reduction in material intensity, and application of clean and resource-efficient technologies. The purpose of this scenario is to present global solutions for economic, social, and environmental sustainability, including improved equity, yet without additional climate initiatives. The characteristics of three scenarios are shown in Table 1.

\subsection{3. $R B F A N N$}

Radial base function network is a suitable ANN for supervised learning problems as regression, classification, and time series prediction. This network has usually three layers:

1. Input layer. In this layer, the number of nodes is equal to that of datasets. Input layer in this research has two nodes (annual precipitation depth and mean annual temperature are data sets).

2. Hidden layer. In this layer, the optimum number of nodes and its parameters must be determined by trial-error method. This layer develops a nonlinear adaptation between inputs and outputs 
Table 1. The characteristics of three scenarios A1B, B1, and A2 [24].

\begin{tabular}{|c|c|c|c|c|c|c|c|c|c|c|}
\hline \multirow{2}{*}{ Characteristics } & \multirow{2}{*}{1990} & \multicolumn{3}{|c|}{ A1B } & \multicolumn{3}{|c|}{ A2 } & \multicolumn{3}{|c|}{ B1 } \\
\hline & & 2020 & 2050 & 2100 & 2020 & 2050 & 2100 & 2020 & 2050 & 2100 \\
\hline $\begin{array}{l}\text { Population } \\
\text { (billion) }\end{array}$ & 5.3 & 7.4 & 8.7 & 7.1 & 8.2 & 11.3 & 15.1 & 7.6 & 8.7 & 7 \\
\hline $\begin{array}{c}\text { Share of coal } \\
\text { in primary energy }(\%)\end{array}$ & 24 & 23 & 14 & 4 & 22 & 30 & 53 & 22 & 21 & 8 \\
\hline $\begin{array}{l}\text { Share of zero carbon } \\
\text { in primary energy }(\%)\end{array}$ & 18 & 16 & 36 & 65 & 8 & 18 & 28 & 21 & 30 & 52 \\
\hline $\begin{array}{c}\text { Carbon dioxide } \\
(\mathrm{GtC} / \mathrm{yr})\end{array}$ & 7.1 & 12.6 & 16.4 & 13.5 & 12.2 & 17.4 & 29.1 & 10.6 & 11.3 & 4.2 \\
\hline
\end{tabular}

and converts nonlinear patterns to separable linear patterns. This layer utilizes a nonlinear activation function. This function is:

$$
F(x)=\sum_{i=1}^{N} w_{i} h\left(\left\|x-u_{i}\right\|\right),
$$

where $N$ is the number of neurons in the hidden layer, $u_{i}$ is the center vector for neuron $i$, and $w_{i}$ is the weight of neuron $i$ in the linear output neuron.

The radial basis function is commonly Gaussian basis function.

$$
h\left(\left\|x-u_{i}\right\|\right)=\exp \left[\frac{-\left\|x-u_{i}\right\|^{2}}{\sigma_{i}}\right],
$$

where $\sigma_{i}$ is the Kernel weight factor for neuron $i$.

3. Output layer. This layer produces a linear combination from $w_{i}$. The number of the nodes is equal to that of outputs of network. In this research, this layer has one node (maximum intensity of rainfall for each duration is output of ANN).

Figure 2 shows a RBF ANN and Figure 3 shows a flowchart of research methodology.

\section{Results and discussion}

Results of this study are stated in the following steps:

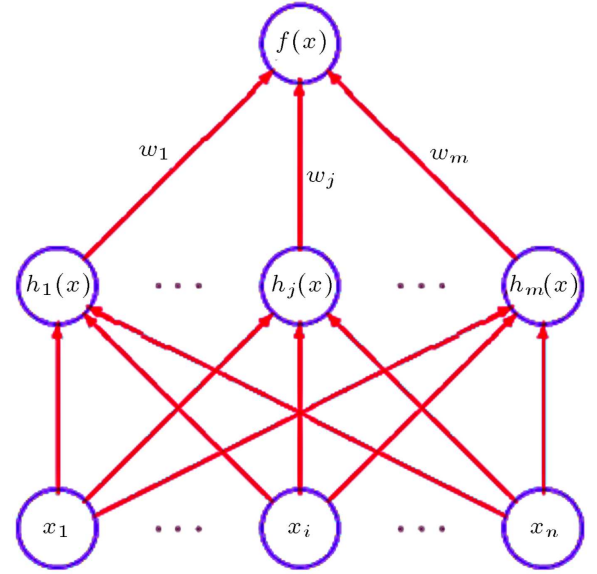

Figure 2. A radial base function artificial neural network $[25]$.

Step 1: Preparation of precipitation data in base time period and determination of IDF curves using a suitable probability distribution. Khuzestan Water and Power Authority (KWPA) has recorded the depth of occurred rainfalls in 15-minute time steps at the Baghmalek climatic station. These rainfalls occurred in a 40-year period (1974-2013). By using such recorded data, maximum annual intensity of precipitation was extracted for different durations $(15,30$, and 45 minutes and 1, 2, 3, 6, and 12 hours). Table 2 illustrates

\begin{tabular}{|c|c|c|c|c|c|c|c|c|}
\hline Duration & $15 \mathrm{~min}$ & $30 \mathrm{~min}$ & $45 \mathrm{~min}$ & 1 hour & 2 hours & 3 hours & 6 hours & 12 hours \\
\hline $\begin{array}{c}\operatorname{Min}(\mathrm{mm} / \mathrm{hr}) \\
(\text { year })\end{array}$ & $\begin{array}{c}16.8 \\
(2013)\end{array}$ & $\begin{array}{c}8.4 \\
(2004)\end{array}$ & $\begin{array}{c}5.6 \\
(2004)\end{array}$ & $\begin{array}{c}5.1 \\
(2004,2013)\end{array}$ & $\begin{array}{c}2.55 \\
(2004)\end{array}$ & $\begin{array}{c}1.7 \\
(2004)\end{array}$ & $\begin{array}{c}0.61 \\
(2013)\end{array}$ & $\begin{array}{c}0.7 \\
(1999)\end{array}$ \\
\hline Mean $(\mathrm{mm} / \mathrm{hr})$ & 133.35 & 68.89 & 49.7 & 37.62 & 23.09 & 14.14 & 4.9 & 3.06 \\
\hline $\begin{array}{c}\operatorname{Max}(\mathrm{mm} / \mathrm{hr}) \\
(\text { year })\end{array}$ & $\begin{array}{l}583.20 \\
(2010)\end{array}$ & $\begin{array}{l}291.60 \\
(2010)\end{array}$ & $\begin{array}{l}194.53 \\
(2010)\end{array}$ & $\begin{array}{l}145.90 \\
(2010)\end{array}$ & $\begin{array}{l}73.05 \\
(2010)\end{array}$ & $\begin{array}{l}46.83 \\
(1994)\end{array}$ & $\begin{array}{l}20.48 \\
(1994)\end{array}$ & $\begin{array}{l}10.45 \\
(1994)\end{array}$ \\
\hline
\end{tabular}

Table 2. The minimum, mean and maximum values of maximum annual intensity of precipitation for different durations. 


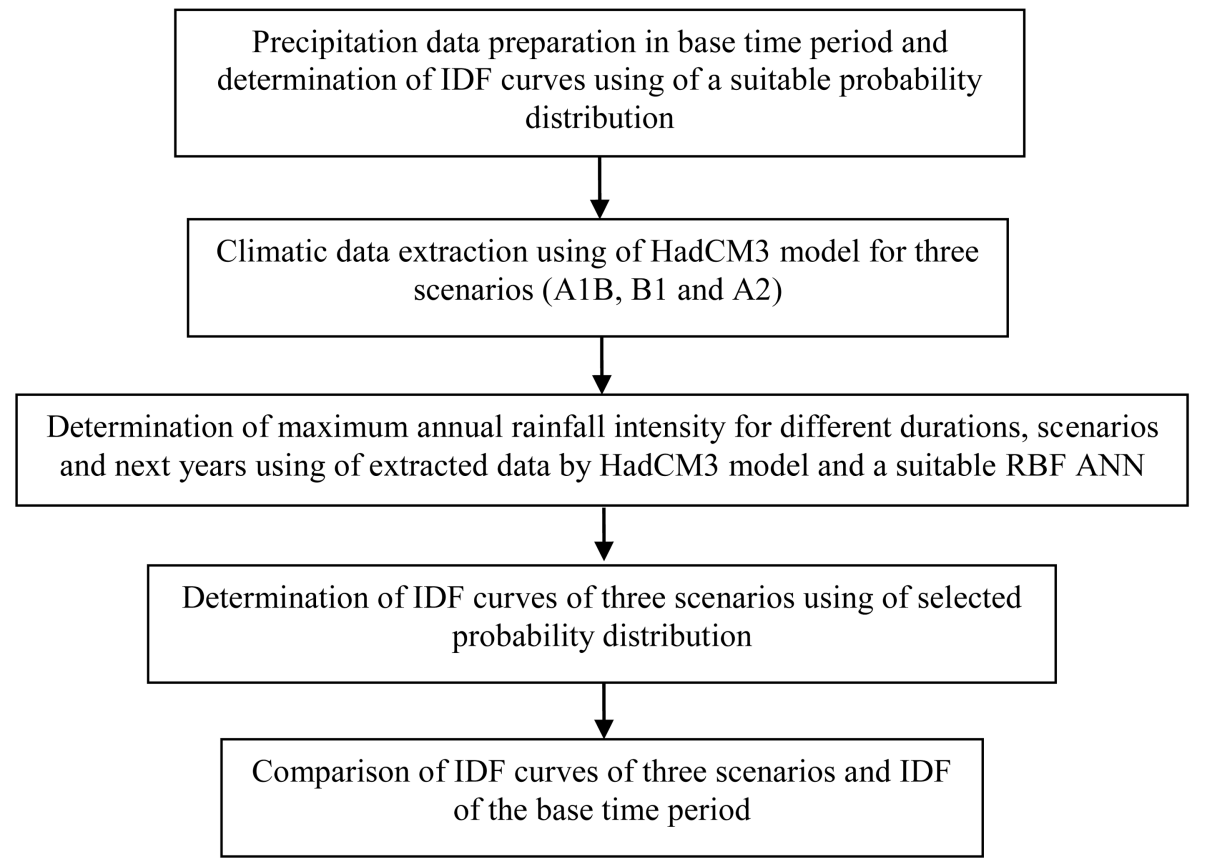

Figure 3. Flowchart of research methodology.

Table 3. Rainfall intensity (mm/hr) for different durations and return periods (1974-2013).

\begin{tabular}{cccccccccc}
\hline \multirow{2}{*}{$\begin{array}{c}\text { Probability } \\
\text { distribution }\end{array}$} & $\begin{array}{c}\text { Return } \\
\text { period (year) }\end{array}$ & $\mathbf{1 5}$ & $\mathbf{3 0}$ & $\mathbf{4 5}$ & $\mathbf{6 0}$ & $\mathbf{1 2 0}$ & $\mathbf{1 8 0}$ & $\mathbf{3 6 0}$ & $\mathbf{7 2 0}$ \\
\cline { 3 - 10 } Gumbel & 2 & 117.08 & 61.02 & 44.40 & 33.64 & 20.67 & 12.72 & 4.31 & 2.76 \\
& 2.3 & 129.03 & 66.80 & 48.29 & 36.56 & 22.44 & 13.77 & 4.74 & 2.98 \\
& 100 & 489.39 & 241.08 & 165.65 & 124.55 & 75.96 & 45.35 & 17.70 & 9.83 \\
& & & & & & & & & \\
Log pearson III & 2 & 53.81 & 31.63 & 23.87 & 18.18 & 11.20 & 6.92 & 2.37 & 1.62 \\
& 2.3 & 113.47 & 73.47 & 77.93 & 51.92 & 34.16 & 18.76 & 6.18 & 2.76 \\
& 100 & 420.39 & 189.16 & 121.79 & 96.36 & 58.36 & 35.99 & 12.27 & 7.85 \\
\hline
\end{tabular}

Table 4. MSE (mm/hr) ${ }^{2}$ of Gumbel and log pearson III probability distributions.

\begin{tabular}{ccccccccc}
\hline Probability & \multicolumn{8}{c}{ Duration (min) } \\
\cline { 2 - 9 } distribution & $\mathbf{1 5}$ & $\mathbf{3 0}$ & $\mathbf{4 5}$ & $\mathbf{6 0}$ & $\mathbf{1 2 0}$ & $\mathbf{1 8 0}$ & $\mathbf{3 6 0}$ & $\mathbf{7 2 0}$ \\
\hline Gumbel & $\underline{17.19}$ & $\underline{5.3}$ & $\underline{3.56}$ & $\underline{2.81}$ & 4.98 & 3.16 & 1.63 & $\underline{0.52}$ \\
Log pearson III & 18 & 7.91 & 4.9 & 4.02 & $\underline{4.01}$ & $\underline{2.68}$ & $\underline{1.56}$ & 0.61 \\
\hline
\end{tabular}

the minimum, mean, and maximum values of maximum annual intensity of precipitation.

To extract IDF curves and determine rainfall intensity for each duration and return period, two conventional probability distributions (Gumbel and log pearson III) were tested by mean square error method. MSE of these distributions was calculated for observed data in the base time period (1974-2013). Table 3 shows calculated rainfall intensity by two probability distributions for different durations and return periods in base time period. Table 4 shows MSE of calculated values by two probability distributions.

For most of durations, MSE of the Gumbel probability distribution is lower than that of the log pearson III probability distribution. Moreover, for durations with low MSE of the log pearson III probability distribution, the difference between MSE of this distribution and MSE of the Gumbel probability distribution is negligible. Therefore, to prepare IDF curves, the Gumbel probability distribution is a suitable distribution. 


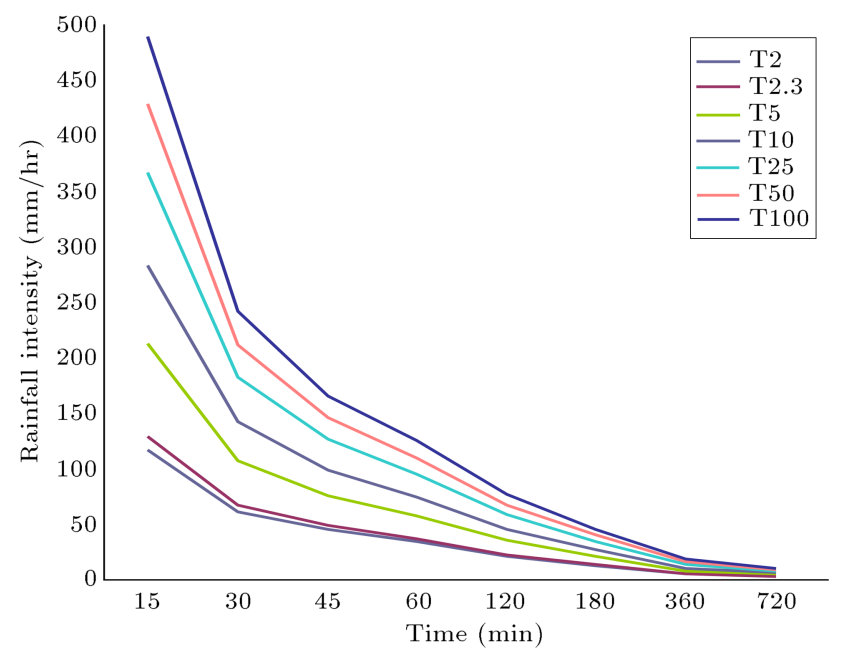

Figure 4. Produced IDF curves using the Gumbel probability distribution (1974-2013).

Therefore, this probability distribution uses production of IDF curves from 1974 to 2013 (Figure 4).

Step 2: Training, validation, and testing of $R B F$ ANN and selection of its optimum parameters. For selection of the optimum values of parameters (number of nodes in hidden layer and the Kernel weight factor), RBF ANN must be trained using observed data in base time period (1974-2013). Annual precipitation depth and mean annual temperature $(2 \times 40=80$ inputs $)$ were introduced to ANN, and outputs included maximum annual rainfall intensity of different durations $(40 \times 8=$ 320 outputs), calculated by ANN. Then, 70, 15 and 15 percents of data were applied to training, validation, and testing of ANN, respectively. RBF ANNs with different number of nodes in hidden layer and the Kernel weight factors were evaluated, whose results are shown in Table 5.

The MSE changes of selected RBF ANN and effects of changes of the number of nodes in hidden layer and the Kernel weight factor on MSE are illustrated in Figures 5 to 7 .

Maximum annual rainfall intensity was calculated by selected RBF ANN for different durations (15, 30 , and 45 minutes and 1, 2, 3, 6, and 12 hours) in base time period. Table 6 shows the minimum, mean, and maximum values of calculated maximum annual

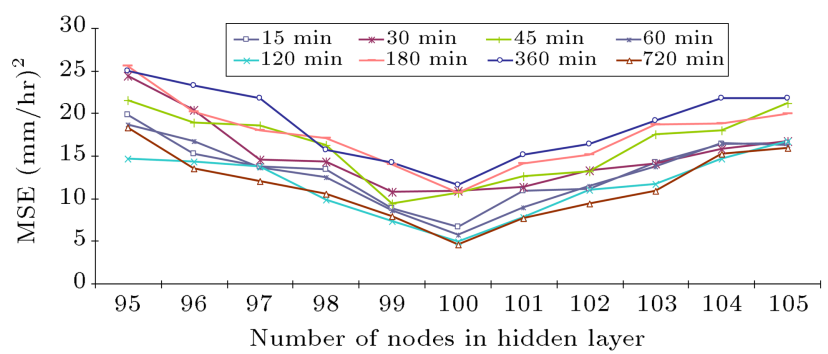

Figure 5. Effects of changes of the number of nodes in hidden layer on MSE.

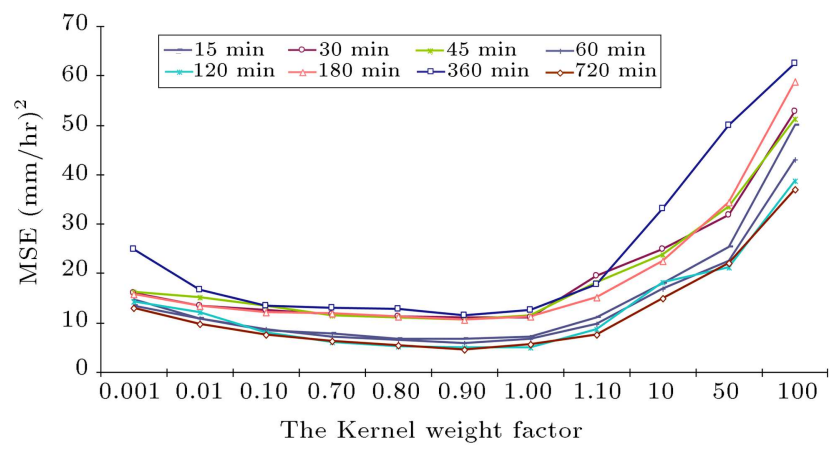

Figure 6. Effects of changes of the Kernel weight factor on MSE.

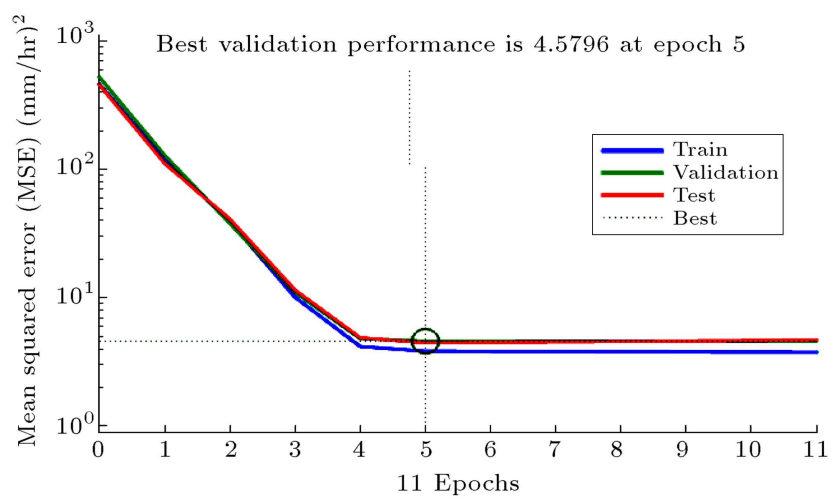

Figure 7. The MSE changes of selected RBF ANN.

rainfall intensity by selected RBF ANN for different durations.

Step 3: $\quad$ Climatic data extraction using the HadCM3 model for three scenarios ( $A 1 B, B 1$, and $A 2)$ : In this research, annual precipitation depth and mean annual temperature have been extracted using the HadCM3

Table 5. The optimum values of parameters of RBF ANN for different durations.

\begin{tabular}{ccccccccc}
\hline Durations (min) & $\mathbf{1 5}$ & $\mathbf{3 0}$ & $\mathbf{4 5}$ & $\mathbf{6 0}$ & $\mathbf{1 2 0}$ & $\mathbf{1 8 0}$ & $\mathbf{3 6 0}$ & $\mathbf{7 2 0}$ \\
\hline $\begin{array}{c}\text { Number of nodes } \\
\text { in hidden layer }\end{array}$ & 100 & 99 & 99 & 100 & 100 & 100 & 100 & 100 \\
$\begin{array}{c}\text { The Kernel } \\
\text { weight factor }\end{array}$ & 0.9 & 0.9 & 0.9 & 0.9 & 0.9 & 0.9 & 0.9 & 0.9 \\
\hline
\end{tabular}


Table 6. The minimum, mean, and maximum values of maximum annual rainfall intensity for different durations (calculated by selected RBF ANN).

\begin{tabular}{|c|c|c|c|c|c|c|c|c|}
\hline Duration & $15 \mathrm{~min}$ & $30 \mathrm{~min}$ & $45 \mathrm{~min}$ & 1 hour & 2 hours & 3 hours & 6 hours & 12 hours \\
\hline $\begin{array}{c}\text { Min }(\mathrm{mm} / \mathrm{hr}) \\
(\text { year })\end{array}$ & $\begin{array}{c}17 \\
(2013)\end{array}$ & $\begin{array}{c}8.5 \\
(2004)\end{array}$ & $\begin{array}{c}5.3 \\
(2004)\end{array}$ & $\begin{array}{c}5.15 \\
(2004,2013)\end{array}$ & $\begin{array}{c}2.3 \\
(2004)\end{array}$ & $\begin{array}{c}1.9 \\
(2004)\end{array}$ & $\begin{array}{c}0.7 \\
(2013)\end{array}$ & $\begin{array}{c}0.65 \\
(1999)\end{array}$ \\
\hline Mean $(\mathrm{mm} / \mathrm{hr})$ & 123.86 & 62.7 & 45.68 & 34.61 & 21.7 & 13.81 & 4.92 & 3.05 \\
\hline $\begin{array}{c}\operatorname{Max}(\mathrm{mm} / \mathrm{hr}) \\
(\text { year })\end{array}$ & $\begin{array}{r}545.3 \\
(2010) \\
\end{array}$ & $\begin{array}{l}323.5 \\
(2010) \\
\end{array}$ & $\begin{array}{l}172.4 \\
(2010) \\
\end{array}$ & $\begin{array}{c}165 \\
(2010) \\
\end{array}$ & $\begin{array}{c}80.4 \\
(2010) \\
\end{array}$ & $\begin{array}{c}45.1 \\
(1994) \\
\end{array}$ & $\begin{array}{c}21.2 \\
(1994) \\
\end{array}$ & $\begin{array}{l}12.14 \\
(1994) \\
\end{array}$ \\
\hline
\end{tabular}

Table 7. The minimum, mean, and maximum values of extracted annual precipitation depth and mean annual temperature for three scenarios (2021-2050).

\begin{tabular}{clccc}
\hline Scenarios & & A1B & B1 & A2 \\
\hline \multirow{2}{*}{$\begin{array}{c}\text { Annual precipitation } \\
\text { depth (mm) }\end{array}$} & Min & 143.63 & 189.44 & 72.67 \\
& Max & 575.75 & 621.16 & 589.84 \\
& & & & \\
Mean annual & Min & 16.19 & 15.6 & 16.31 \\
temperature $\left({ }^{\circ} \mathrm{C}\right)$ & Mean & 17.83 & 17.23 & 17.7 \\
& Max & 19.57 & 18.75 & 19.01 \\
\hline
\end{tabular}

model and the AR4(2007) assessment. The three considered scenarios are B1, A2, and A1B. Annual precipitation depth and mean annual temperature of three scenarios are illustrated in Table 7.

Step 4: Determination of maximum annual rainfall intensity for different durations and scenarios in the next years (2021-2050) using RBF ANN and determination of IDF curves of three scenarios using the Gumbel probability distribution. IDFs of three scenarios are illustrated in Table 8.

Step 5: Comparison of IDF curves of three scenarios with IDF of the base time period. IDF curves of three scenarios and the base time period have been compared, and the results have been observed.

In comparison with IDF curves of the base time period, Table 9 and Figures 8 to 10 illustrate that rainfall intensity increases for different durations and scenarios (return periods less than 2.3 years), while it decreases for different durations and scenarios (return periods more than 100 years). Due to increasing greenhouse gases (especially dioxide carbon) in the future, the number of regular rainfalls will increase and the number of heavy rainfalls will decrease. This study presents the reason for increasing rainfall intensity of return periods less than 2.3 years and decreasing rainfall intensity of return periods more than 2.3 years.

From 2021 to 2050 , the volume of dioxide carbon

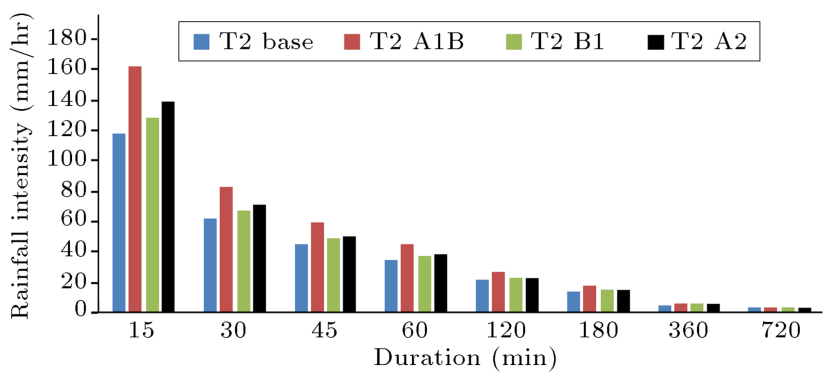

Figure 8. Comparison of rainfall intensity of three scenarios and the base time period for different durations (return period 2 years).

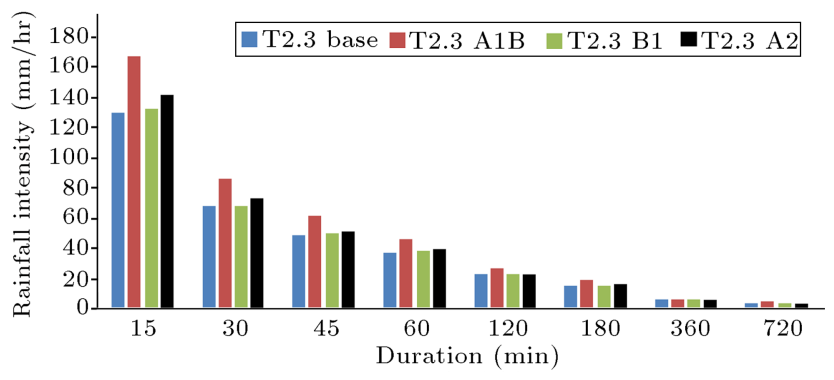

Figure 9. Comparison of rainfall intensity of three scenarios and the base time period for different durations (return periods 2.3 years).

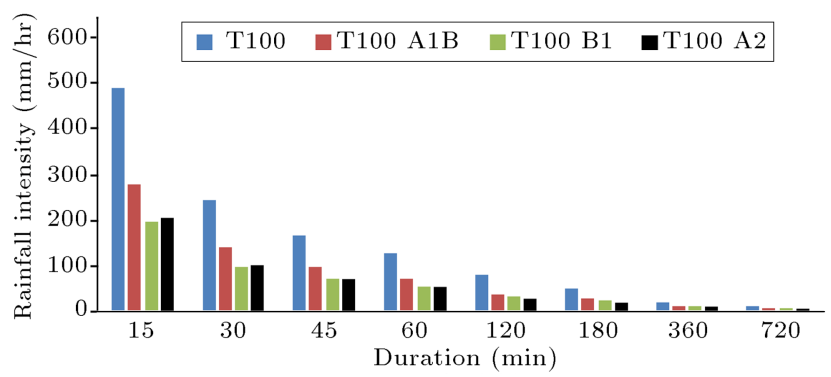

Figure 10. Comparison of rainfall intensity of three scenarios and the base time period for different durations (return periods 100 years).

of $\mathrm{A} 1 \mathrm{~B}$ is more than other scenarios. Therefore, for different return periods and durations, rainfall intensity of $\mathrm{A} 1 \mathrm{~B}$ is higher than other scenarios, while rainfall intensities of B1 and A2 are approximately equal. 
Table 8. IDF of A1B, B1, and A2 scenarios (2021-2050).

\begin{tabular}{|c|c|c|c|c|c|c|c|c|c|}
\hline \multirow{2}{*}{ Return period (year) } & \multirow{2}{*}{ Scenario } & \multicolumn{8}{|c|}{ Duration (min) } \\
\hline & & 15 & 30 & 45 & 60 & 120 & 180 & 360 & 720 \\
\hline \multirow{3}{*}{2} & $\mathrm{~A} 1 \mathrm{~B}$ & 161.38 & 82.58 & 58.61 & 44.51 & 25.49 & 17.21 & 5.29 & 3.22 \\
\hline & B1 & 128.32 & 66.22 & 47.84 & 36.51 & 21.57 & 14.35 & 4.70 & 2.79 \\
\hline & A 2 & 137.97 & 70.62 & 49.74 & 37.84 & 21.68 & 14.69 & 4.90 & 3.10 \\
\hline \multirow{3}{*}{2.3} & $\mathrm{~A} 1 \mathrm{~B}$ & 167.43 & 85.42 & 60.47 & 45.86 & 26.08 & 17.71 & 5.41 & 3.27 \\
\hline & B1 & 131.77 & 67.84 & 48.86 & 37.25 & 21.94 & 14.69 & 4.83 & 2.87 \\
\hline & A 2 & 141.33 & 72.14 & 50.66 & 38.49 & 21.93 & 14.94 & 5.00 & 3.14 \\
\hline \multirow{3}{*}{5} & $\mathrm{~A} 1 \mathrm{~B}$ & 187.91 & 95.05 & 66.77 & 50.42 & 28.07 & 19.40 & 5.81 & 3.41 \\
\hline & B1 & 143.45 & 73.35 & 52.33 & 39.77 & 23.20 & 15.82 & 5.26 & 3.12 \\
\hline & A 2 & 152.70 & 77.27 & 53.76 & 40.67 & 22.79 & 15.78 & 5.34 & 3.31 \\
\hline \multirow{3}{*}{10} & $\mathrm{~A} 1 \mathrm{~B}$ & 210.58 & 105.71 & 73.75 & 55.48 & 30.28 & 21.28 & 6.26 & 3.57 \\
\hline & B1 & 156.38 & 79.45 & 56.17 & 42.55 & 24.60 & 17.08 & 5.73 & 3.40 \\
\hline & A 2 & 165.30 & 82.96 & 57.20 & 43.09 & 23.74 & 16.71 & 5.71 & 3.50 \\
\hline \multirow{3}{*}{25} & $\mathrm{~A} 1 \mathrm{~B}$ & 237.01 & 118.13 & 81.88 & 61.37 & 32.85 & 23.47 & 6.78 & 3.75 \\
\hline & B1 & 171.45 & 86.55 & 60.64 & 45.79 & 26.22 & 18.55 & 6.28 & 3.72 \\
\hline & A 2 & 179.98 & 89.59 & 61.20 & 45.91 & 24.85 & 17.80 & 6.14 & 3.71 \\
\hline \multirow{3}{*}{50} & $\mathrm{~A} 1 \mathrm{~B}$ & 256.65 & 127.36 & 87.92 & 65.75 & 34.76 & 25.09 & 7.17 & 3.89 \\
\hline & B1 & 182.65 & 91.83 & 63.96 & 48.21 & 27.43 & 19.64 & 6.69 & 3.96 \\
\hline & $\mathrm{A} 2$ & 190.89 & 94.52 & 64.18 & 48.00 & 25.67 & 18.61 & 6.47 & 3.87 \\
\hline \multirow{3}{*}{100} & $\mathrm{~A} 1 \mathrm{~B}$ & 276.10 & 136.50 & 93.91 & 70.09 & 36.66 & 26.70 & 7.55 & 4.02 \\
\hline & B1 & 193.74 & 97.06 & 67.26 & 50.59 & 28.63 & 20.71 & 7.09 & 4.20 \\
\hline & $\mathrm{A} 2$ & 201.70 & 99.40 & 67.12 & 50.08 & 26.49 & 19.41 & 6.78 & 4.03 \\
\hline
\end{tabular}

Table 9. Maximum increase and decrease of rainfall intensity of three scenarios in comparison with that of rainfall intensity of the base time period.

\begin{tabular}{ccccccc}
\hline \multirow{2}{*}{ Scenario } & \multicolumn{2}{c}{ Maximum increase (\%) } & \multicolumn{3}{c}{ Maximum decrease (\%) } \\
\cline { 2 - 7 } & $\begin{array}{c}\text { Value } \\
(\%)\end{array}$ & $\begin{array}{c}\text { Duration } \\
(\mathbf{m i n})\end{array}$ & $\begin{array}{c}\text { Return } \\
\text { period } \\
(\text { year })\end{array}$ & $\begin{array}{c}\text { Value } \\
\mathbf{( \% )}\end{array}$ & $\begin{array}{c}\text { Duration } \\
(\mathbf{m i n})\end{array}$ & $\begin{array}{c}\text { Return } \\
\text { period } \\
\text { (year) }\end{array}$ \\
\hline A1B & 37.84 & 15 & 2 & 59.04 & 720 & 100 \\
B1 & 12.83 & 180 & 2 & 62.31 & 120 & 100 \\
A2 & 17.84 & 15 & 2 & 65.13 & 120 & 100 \\
\hline
\end{tabular}

\section{Conclusion}

This study employed developed integrated method for producing IDF curves and evaluating effects of the climatic changes on them. This method (1) prepared precipitation data and extracted IDF curves for the base time period by using the Gumbel probability distribution, (2) prepared annual rainfall depth and mean annual temperature using the HadCM3 model for three scenarios of $\mathrm{A} 1 \mathrm{~B}, \mathrm{~B} 1$, and $\mathrm{A} 2$, (3) deter- mined maximum annual rainfall intensity for different durations and scenarios using a RBF ANN (optimum parameters of this network were determined by testing different parameters), (4) determined IDF curves of three scenarios by the Gumbel probability distribution, and (5) compared IDF curves of three scenarios and IDF curves of the base time period.

With an increase in population number and in volume of greenhouse gases as dioxide carbon, humidity increases, thus increasing the number of regular rainfall 
and rainfall intensity for return periods less than 2.3 years. On the other hand, temperature increases, too. The same phenomenon is the reason for a decrease in the number of heavy rainfall and rainfall intensity for return periods more than 2.3 years.

The maximum and minimum volumes of greenhouse gases belong to $\mathrm{A} 1 \mathrm{~B}$ and $\mathrm{B} 1$ scenarios, respectively (from 2021 to 2050). Therefore, the maximum and minimum rainfall intensities for return periods less than 2.3 years belong to $\mathrm{A} 1 \mathrm{~b}$ and $\mathrm{B} 1$, too. By increasing temperature and volume of greenhouse gases, the number and rainfall intensity of showers increase, and duration of showers decreases. Therefore, for return periods more than 2.3 years and durations less than 60 minutes, the maximum and minimum rainfall intensities belong to $\mathrm{A} 1 \mathrm{~B}$ and $\mathrm{B} 1$, respectively. However, for durations more than 60 minutes, rainfall intensities of three scenarios are approximately equal.

For different scenarios, this study showed that rainfall intensity would decrease for large return periods. Precipitations with great return periods are an important resource of river water supply. The Baghmalek climatic station is located in the Zard River watershed. The Zard River is a tributary of the Jarahi River. Therefore, the flow discharge of these rivers will decrease in the future. Managers of water resources, authorities of KWPA, and water engineers must modify water supply plans for drinkable, industrial, and agricultural water demands.

\section{References}

1. Garcia-Bartual, R. and Schneider, M. "Estimating maximum expected short-duration rainfall intensities from extreme convective storms", Phys. Chem. Earth. Pt. B., 26(9), pp. 675-681 (2001).

2. Yu, P.S., Yang, T.C., and Lin, C.S. "Regional rainfall intensity formulas based on scaling property of rainfall", J. Hydrol., 295(1-4), pp. 108-123 (2004).

3. Madsen, H., Arnbjerg-Nielsen, K., and Mikkelsen, P.S. "Update of regional intensity-duration-frequency curves in Denmark: tendency towards increased storm intensities", Atmos. Res., 92(3), pp. 343-349 (2009).

4. Agilan, V. and Umamahesh, N.V. "What are the best covariates for developing non-stationary rainfall intensity-duration-frequency relationship?", $A d v$. Water Resour., 101, pp. 11-22 (2017).

5. Huang, Y.F., Mirzaei, M., and Amin, M.Z.M. "Uncertainty quantification in rainfall intensity duration frequency curves based on historical extreme precipitation quantiles", Procedia Eng., 154, pp. 426-432 (2016).

6. Fadhel, S., Rico-Ramirez, M.A., and Han, D. "Uncertainty of Intensity-Duration-Frequency (IDF) curves due to varied climate baseline periods", J. Hydrol., 547, pp. 600-612 (2017).
7. Bezak, N., S̆raj, M. and Mikos̆, M. "Copula-based IDF curves and empirical rainfall thresholds for flash floods and rainfall-induced landslides", J. Hydrol., 541(Part A), pp. 272-284 (2016).

8. Khan, M.S., Coulibaly, P., and Dibike, Y. "Uncertainty analysis of statistical downscaling methods", J. Hydrol., 319(1-4), pp. 357-382 (2006).

9. Wang, H. and Lau, K.M. "Atmospheric hydrological cycle in the tropics in twentieth century coupled climate simulations", Int. J. Climatol., 26(5), pp. 655678 (2006).

10. Hashmi, M.Z., Shamseldin, A.Y., and Melville, B.W. "Comparison of SDSM and LARS-WG for simulation and downscaling of extreme precipitation events in a watershed", Stoch. Env. Res. Risk A., 25(4), pp. 475484 (2011).

11. Gulacha, M.M. and Mulungu, D.M.M. "Generation of climate change scenarios for precipitation and temperature at local scales using SDSM in Wami-Ruvu River Basin Tanzania", Phys. Chem. Earth. Pts. A/B/C., 100, pp. 62-72 (2017).

12. Kuok, K.K., Mah, Y.S., Imteaz, M.A., and Kueh, S.M. "Comparison of future intensity duration frequency curve by considering the impact of climate change: case study for Kuching city", Int. J. River Basin Manag., 14(1), pp. 47-55 (2016).

13. Mailhot, A., Duchesne, S., Caya, D., and Talbot, G. "Assessment of future change in intensity-durationfrequency (IDF) curves for Southern Quebec using the Canadian Regional Climate Model (CRCM)", $J$. Hydrol., 347(1-2), pp. 197-210 (2007).

14. Alam, M.S. and Elshorbagy, A. "Quantification of the climate change-induced variations in intensityduration-frequency curves in the Canadian Prairies", J. Hydrol., 527, pp. 990-1005 (2015).

15. Kuo, C.C., Gan, T.Y., and Hanrahan, J.L. "Precipitation frequency analysis based on regional climate simulations in Central Alberta", J. Hydrol., 510, pp. 436-446 (2014).

16. Lima, C.H.R., Kwon, H.H., and Kim, J.Y. "A Bayesian beta distribution model for estimating rainfall IDF curves in a changing climate", J. Hydrol., 540, pp. 744-756 (2016).

17. Agilan, V. and Umamahesh, N.V. "Is the covariate based non-stationary rainfall IDF curve capable of encompassing future rainfall changes?", J. Hydrol., 541(Part B), pp. 1441-1455 (2016).

18. Simonovic, S.P., Schardong, A., Sandink, D., and Srivastav, R. "A web-based tool for the development of intensity duration frequency curves under changing climate", Environ. Modell. Softw., 81, pp. 136-153 (2016).

19. DeGaetano, A.T. and Castellano, C.M. "Future projections of extreme precipitation intensity-durationfrequency curves for climate adaptation planning in New York State", Clim. Serv., 5, pp. 23-35 (2017). 
20. Kalantari, N., Rangzan, K., Thigale, S.S. and Rahimi, M.H. "Site selection and cost-benefit analysis for artificial recharge in the Baghmalek plain, Khuzestan province, southwest Iran", Hydrogeol. J., 18(3), pp. 761-773 (2010).

21. Gordon, C., Cooper, C., Senior, C.A., Banks, H., Gregory, J.M., Johns, T.C., Mitchell, J.F.B., and Wood, R.A. "The simulation of SST, sea ice extents and ocean heat transports in a version of the Hadley Centre coupled model without flux adjustments", Clim. Dynam., 16(2-3), pp. 147-168 (2000).

22. Pope, V.D., Gallani, M.L., Rowntree, P.R., and Stratton, R.A. "The impact of new physical parameterizations in the Hadley Centre climate model: HadAM3", Clim. Dynam., 16(2-3), pp. 123-146 (2000).

23. Collins, M., Tett, S.F.B., and Cooper, C. "The internal climate variability of HadCM3, a version of the Hadley Centre coupled model without flux adjustments", Clim. Dynam., 17(1), pp. 61-81 (2001).

24. Summary for policymakers-Emissions scenarios "A special report of working group III of the intergovernmental panel on climate change", (2000).
25. Orr, M.J.L., Introduction to Radial Basis Function Networks, Centre for Cognitive Science, 67 p, University of Edinburgh, Edinburgh, Scotland (1996).

\section{Biographies}

Arash Adib is an Associate Professor at Shahid Chamran university, Ahvaz, Iran. He has almost 50 journal papers and 120 conference papers. He accomplished 3 research projects for water and energy ministry of Iran (Khuzestan Water and Power Authority). He received a scholarship from British Council in 2004 and achieved Iranian superior researcher medal in December 2012. He was a supervisor of almost $50 \mathrm{MSc}$ theses and $6 \mathrm{PhD}$ theses.

Saied Ghafari Rad was a water resources engineering student at the Civil Engineering Department, Engineering Faculty, Shahid Chamran University, Ahvaz, Iran. His supervisor was Arash Adib. He obtained his MSc degree in February 2017. He has two conference papers. 